\title{
Next-Generation Sequencing Reveals Potential Predictive Biomarkers and Targets of Therapy for Urothelial Carcinoma in Situ of the Urinary Bladder

Stefan Garczyk, ${ }^{*}$ Nadina Ortiz-Brüchle, * Ursula Schneider, * Isabella Lurje, * Karolina Guricova, ${ }^{*}$ Nadine T. Gaisa, * Eva Lorsy, Katharina Lindemann-Docter, ${ }^{*}$ Axel Heidenreich, ${ }^{\ddagger \S}$ and Ruth Knüchel ${ }^{*}$

From the Institute of Pathology* and the Department of Urology, ${ }^{\S}$ University Hospital Rheinisch-Westfälische Technische Hochschule (RWTH) Aachen, Aachen; and the Departments of Internal Medicine I $I^{\dagger}$ and Urology, ${ }^{\ddagger}$ University Hospital Cologne, Cologne, Germany

\author{
Accepted for publication \\ October 8, 2019. \\ Address correspondence to \\ Stefan Garczyk, Ph.D., Institute \\ of Pathology, University Hos- \\ pital Rheinisch-Westfälische \\ Technische Hochschule \\ (RWTH) Aachen, Pauwelsstr. \\ 30, 52074 Aachen, Germa- \\ ny. E-mail: sgarczyk@ \\ ukaachen.de.
}

\begin{abstract}
Bacillus Calmette-Guérin instillation after removal of the tumor is the first line of treatment for urothelial carcinoma in situ (CIS), the precursor lesion of most muscle-invasive bladder cancers. Bacillus Calmette-Guérin therapy fails in $>50 \%$ of cases, and second-line radical cystectomy is associated with overtreatment and drastic lifestyle consequences. Given the need for alternative bladder-preserving therapies, we identified genomic alterations (GAs) in urothelial CIS having the potential to predict response to targeted therapies. Laser-capture microdissection was applied to isolate 30 samples (25 CIS and 5 muscle controls) from 26 fresh-frozen cystectomy specimens. Targeted next-generation sequencing of 31 genes was performed. The panel comprised genes frequently affected in muscleinvasive bladder cancer of nonpapillary origin, focusing on potentially actionable GAs described to predict response to approved targeted therapies or drugs that are in registered clinical trials. Of CIS patients, $92 \%$ harbored at least one potentially actionable GA, which was identified in TP53/cell cycle pathway-related genes (eg, TP53 and MDM2) in 72\%, genes encoding chromatin-modifying proteins (eg, ARID1A and KDM6A) in 68\%, DNA damage repair genes (eg, BRCA2 and ATM) in 60\%, and phosphatidylinositol 3-kinase/mitogen-activated protein kinase pathway genes (eg, ERBB2 and FGFR1) in $36 \%$ of the cases. These data might help guide the selection of targeted therapies to be investigated in future clinical CIS trials, and they may provide a basis for future mechanistic studies of urothelial CIS pathogenesis. (Am J Pathol 2020, 190: 323-332; https://doi.org/10.1016/j.ajpath.2019.10.004)
\end{abstract}

With an estimated number of 380,000 new cases and 150,000 deaths per year worldwide, bladder cancer is the most common malignancy of the urinary tract. ${ }^{1}$ More than $90 \%$ of all bladder tumors diagnosed in Europe and North America are urothelial carcinomas. ${ }^{2}$ Most bladder cancers present as non-muscle-invasive, low-grade papillary carcinomas, characterized by FGFR3 gene alterations and an excellent prognosis (5-year survival of approximately $90 \%$ ). These tumors infrequently progress to muscle-invasive disease but frequently recur. In contrast, muscle-invasive bladder cancer (MIBC) is associated with an unfavorable prognosis (5-year survival $<50 \%$ ) and a high risk of progression to metastasis. ${ }^{2}$ Most MIBC cases arise via carcinoma in situ (CIS), a flat high-grade lesion associated with TP53 mutations. CIS is found in approximately $10 \%$ of all patients diagnosed with non-muscle-invasive bladder cancer (NMIBC). ${ }^{3}$ The fraction of primary (isolated) CIS is estimated to be $3 \%$ of all patients diagnosed with bladder cancer. ${ }^{4}$ It is estimated that, without any treatment, $40 \%$ to $60 \%$ of CIS patients develop muscle invasion within 5 years after diagnosis. ${ }^{5}$ Currently, therapy for bladder cancer, including CIS, is mainly based on non-specific treatments [ie, chemotherapy or bacillus Calmette-Guérin (BCG) immunotherapy in addition to surgery], depending on the

Supported by the START-Program of the Faculty of Medicine, Rheinisch-Westfälische Technische Hochschule (RWTH) Aachen, grant 06/17 (S.G.).

S.G. and N.O.-B. contributed equally to this work.

Disclosures: None declared. 
risk estimation for the disease diagnosed. ${ }^{6,7}$ Recently, the approval of immune checkpoint inhibitors by the US Food and Drug Administration and the European Medicines Agency has opened new therapeutic options for patients with advanced bladder cancer. ${ }^{8}$ For urothelial bladder cancer, immune checkpoint inhibitor drugs have been approved for the treatment of patients with metastatic bladder cancer as second-line therapy in the post-platinum setting or for cisplatin-ineligible individuals in first line if patients exhibit a combined positive score $>10 \% .^{9}$ Although newgeneration immunotherapies have been shown to result in durable responses and seem to be relatively well tolerated, most patients do not respond because of primary or acquired resistance mechanisms. ${ }^{10}$ For CIS patients, intravesical BCG-based immunotherapy after transurethral resection of tumor cells remains the standard of care, as recommended by the European Association of Urology and the American Urological Association. ${ }^{6,11}$ However, it is estimated that BCG therapy fails in $>50 \%$ of cases, ${ }^{5}$ caused by cessation of treatment because of toxicity or resistance to BCG immunotherapy. ${ }^{12}$ Radical cystectomy is recommended as second-line treatment in case of BCG failure. ${ }^{6,11}$ Although early radical cystectomy is associated with an excellent tumor-specific survival, ${ }^{13}$ the rate of overtreatment is assumed to be up to $50 \%$ and radical cystectomy is a morbid surgery significantly impacting quality of life. ${ }^{14}$ Taken together, there is large need for alternative bladderpreserving therapies for urothelial CIS, reflected by the wide landscape of active clinical trials in high-grade NMIBC. ${ }^{14}$

In recent years, advances in next-generation sequencing (NGS) technologies have led to substantial progress in the molecular characterization of several diseases, including bladder cancer, and thereby the identification of potential biomarkers and candidate therapeutic targets. ${ }^{15-20}$ Although most of the work focused on advanced bladder cancer, ${ }^{15-17,20}$ fewer advances have been made regarding NMIBC. ${ }^{18,19}$ Especially the genomic alterations (GAs) underlying the preinvasive CIS, the precursor lesion of fatal MIBC, have been characterized insufficiently so far. ${ }^{21}$ In this study, laser-capture microdissection (LCM) and targeted NGS were combined to identify therapeutically actionable GAs [mutations and copy number variations $(\mathrm{CNVs})]$ in a cohort of fresh-frozen CIS.

\section{Materials and Methods}

\section{Patients and Sample Preparation}

From 26 cryopreserved cystectomy specimens, 30 samples ( 25 urothelial CIS and 5 smooth muscle control specimens) were isolated by LCM. The 26 patients were treated by cystectomy at the University Hospital RWTH Aachen (Aachen, Germany) between 2005 and 2011 and were retrospectively included in the present study. The study was conducted at the University Hospital RWTH Aachen in accordance with local institutional review board-approved protocols of the Medical Faculty of the RWTH Aachen University (approval number EK 291/16) and the principles expressed in the Declaration of Helsinki. The clinicopathologic parameters for the 26 cystectomy cases are summarized in Table 1 and Supplemental Table S1. The pathologic diagnosis of each urothelial CIS case as well as the absence of cancer cells in smooth muscle controls (distant from tumor areas) were confirmed on hematoxylin and eosin-stained slides by an experienced uropathologist (R.K.) before LCM-based isolation of cells. Moreover, great care has been taken to isolate mere CIS regions without any contact to invasive areas. Figure 1 shows a hematoxylin and eosin-stained tissue section of an exemplary cryopreserved CIS sample that is part of our CIS cohort.

For LCM of CIS (and smooth muscle) cells from the cryoconserved cystectomy specimens, ethanol-fixed, methylene blue-stained tissue sections $(10 \mu \mathrm{m}$ thick $)$ were prepared on nuclease- and nucleic acid-free membrane slides (Zeiss, Oberkochen, Germany) to isolate an area of 6 to $10 \times 10^{6} \mu \mathrm{m}^{2}$ per case using the PALM MicroBeam IP 230VZ (Zeiss) and adhesive caps (Zeiss). Control hematoxylin and eosin slides were prepared after every 10 sections to ensure the histology on the sample slides. DNA was extracted using the QIAamp DNA Micro kit (Qiagen, Hilden, Germany) and was quantified by a Qubit fluorometric assay (Thermo Fisher Scientific, Waltham, MA). To assess the quality of isolated DNA, a real-time quantitative PCR-based method using the TruSeq FFPE DNA Library Prep QC kit (Illumina, San Diego, CA) was applied.

\section{Library Preparation and Targeted NGS}

Genomic target regions for NGS analysis were selected as follows: to identify common GAs (mutations and CNVs) potentially inherent in CIS, publicly available sequencing data for MIBC of nonpapillary origin of The Cancer Genome Atlas network, ${ }^{15}$ accessible via the cBio cancer genomics portal version 3.1.0, ${ }^{22}$ were used. Of these data, potentially druggable GAs in genes impacting the selection of targeted anticancer therapies on the market or that are in registered clinical trials were further studied (Supplemental Table S2). Libraries were generated applying the TruSeq Costum Amplicon Low Input kit (Illumina), according to the manufacturer's instructions. In brief, at least $10 \mathrm{ng}$ of high-quality DNA and $20 \mathrm{ng}$ of medium-quality DNA (as determined by TruSeq FFPE DNA Library Prep QC kit) were used for hybridizing the custom target gene oligonucleotide pools. To improve the validity of the sequencing data, a dual-strand sequencing protocol making use of two sets of custom target gene oligonucleotide pools (named CATA and CATB) was applied, enabling sequence analysis of both complementary DNA strands. Subsequent to hybridization and an extension-ligation step, target regions were amplified using unique index adapter combinations 
Table 1 Clinicopathologic Data of the CIS Patients Analyzed in This Study

\begin{tabular}{|c|c|c|c|c|c|c|c|c|}
\hline Sample ID & Cystectomy & Sex & Age, years & Tumor grade & pT & $\mathrm{pN}$ & $\mathrm{pM}$ & Pretreatment \\
\hline CIS01 & 1 & $M$ & 82 & G3 & pT3 & 1 & 0 & No \\
\hline CISO2 & 2 & $\mathrm{~F}$ & 66 & G3 & pT4 & 0 & NA & No \\
\hline MU05 & 2 & $\mathrm{~F}$ & 66 & G3 & pT4 & 0 & NA & No \\
\hline CISO3 & 3 & M & 73 & G3 & рT3a & 0 & NA & No \\
\hline CISO4 & 4 & $M$ & 43 & G3 & pT2 & 0 & NA & No \\
\hline CISO5 & 5 & $M$ & 75 & G3 & pT1 & 0 & NA & No \\
\hline CIS08 & 8 & $\mathrm{~F}$ & 77 & G3 & рT3a & 1 & NA & No \\
\hline CISO9 & 9 & M & 81 & G3 & pT3b & 0 & NA & No \\
\hline CIS10 & 10 & M & 72 & G3 & pT2a & 0 & NA & Yes \\
\hline CIS11 & 11 & M & 50 & G3 & pT2 & 0 & 1 & No \\
\hline CIS13 & 12 & $\mathrm{~F}$ & 70 & G3 & рT3a & 1 & NA & No \\
\hline CIS14 & 13 & M & 77 & G3 & pT2 & 0 & NA & Yes \\
\hline CIS18 & 17 & M & 76 & G3 & рT3a & 0 & NA & No \\
\hline MU04 & 18 & $\mathrm{~F}$ & 62 & G3 & pT2 & 0 & NA & No \\
\hline CIS20 & 19 & $M$ & 79 & G3 & pT3 & 2 & NA & No \\
\hline CIS21 & 20 & $\mathrm{~F}$ & 75 & G3 & рT2a & 0 & NA & No \\
\hline MU01 & 20 & $\mathrm{~F}$ & 75 & $\mathrm{G} 3$ & рT2a & 0 & NA & No \\
\hline CIS22 & 21 & M & 61 & G2 high grade & pT1b & 0 & NA & No \\
\hline CIS23 & 22 & M & 57 & $\mathrm{G} 3$ & pTis & 0 & NA & No \\
\hline MU03 & 22 & M & 57 & $\mathrm{G} 3$ & pTis & 0 & NA & No \\
\hline CIS24 & 23 & $M$ & 63 & G2 high grade & pT1 & 0 & NA & No \\
\hline CIS25 & 24 & M & 69 & G3 & рT3a & NA & NA & Yes \\
\hline CIS26 & 25 & M & 65 & G3 & pT1a & 0 & NA & Yes \\
\hline
\end{tabular}

CIS, carcinoma in situ; F, female; ID, identification; M, male; MU, smooth muscle sample; NA, not available; pM, distant metastasis status; pN, regional lymph node status; $\mathrm{pT}$, primary tumor classification.

(Illumina). After cleanup, library quality control was assessed by bioanalyzer analysis (Agilent Technologies, Santa Clara, CA). Finally, normalized libraries were sequenced on a NextSeq 500 platform (Illumina) using a NextSeq 500/550 Mid Output kit $(2 \times 150$ cycles; Illumina). For single-nucleotide variant analysis, bam-file generation was performed with the DNA amplicon module version 2.0.0 (Basespace; Illumina). Single-nucleotide variant analysis was conducted using Sequence Pilot Software version 4.4 (SeqNext module; JSI Medical Systems, Ettenheim, Germany). For all analyzed samples, region of interest coverage was $>96 \%$ at $300 \times$. Missense and silent variants with an allele frequency $>2 \%$ in the normal population [according to 1000 Genomes (http://www. internationalgenome.org, last accessed September 2, 2019) or dbSNP version 153 (https://www.ncbi.nlm.nih.gov/snp, last accessed September 27, 2019)] and nonsplicing-relevant silent and intronic variants in general were considered nonpathogenic. In addition, all untranslated region and missense variants annotated as benign or likely benign in the ClinVar database (https:// www.ncbi.nlm.nih.gov/clinvar, last accessed September 27,
2019) were also excluded. The TERT gene promoter was checked for the two known recurrent mutations: c. $-124 \mathrm{C}>\mathrm{T}$ and c. $-146 \mathrm{C}>\mathrm{T}$. The cutoff for the variant allele frequency was set to $5 \%$. As reference genome for panel design, hg19 was used, whereas hg38 served as reference genome for mutation annotation. For CNV analysis, a recently developed in-house algorithm (validated using three NGS panels; $n=144$ samples), based on an exponential growth model for amplification of PCR products, was applied. For every gene analyzed for CNVs, at least 10 amplicons were included in the panel design. Coverage data were normalized; and amplicon clustering, based on the PCR efficiency among all samples, was performed (for each amplicon). Genes were considered harboring a CNV if at least $30 \%$ of the amplicons of a gene were recognized as outliers in most of the (five) response models built within a cluster. The underlying reference genome for the panel design was hg19.

The raw sequencing data of this study are deposited in the National Center for Biotechnology Information Sequence Read Archive version 2.15.0 (https://www.ncbi.nlm.nih.gov/ sra; accession number PRJNA551281). 


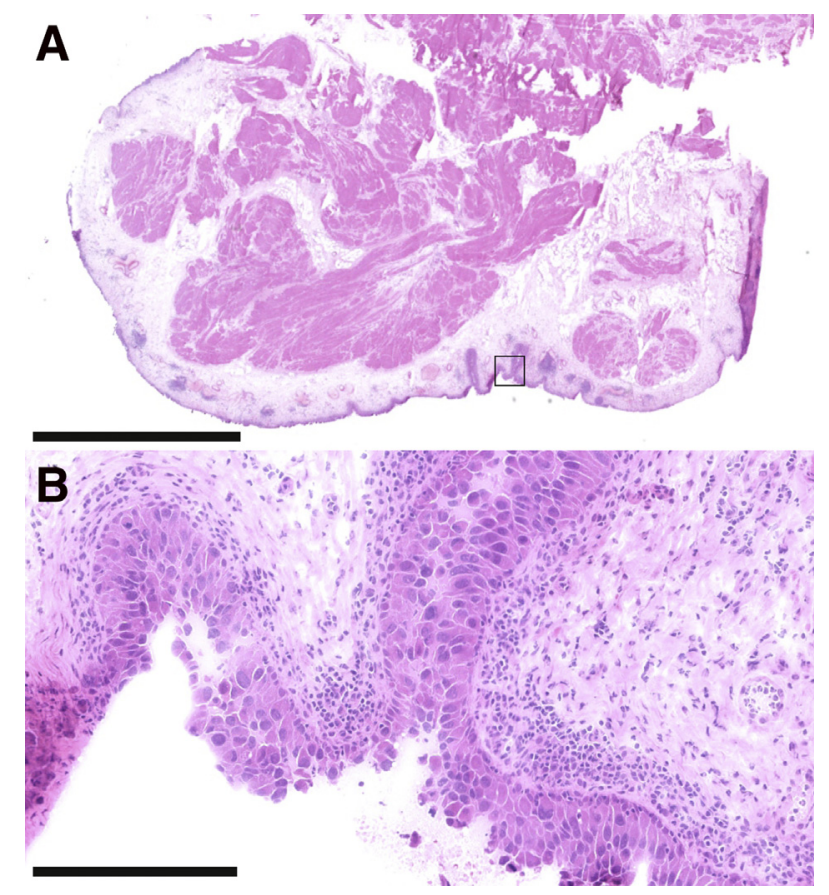

Figure 1 Hematoxylin and eosin-stained tissue section of an exemplary cryopreserved carcinoma in situ (CIS) sample used for laser-capture microdissection. A: Overview of a specimen with maintained luminal urothelium, edematous stroma, and lymphofollicular infiltrates. No invasive tumor is seen in proximity, and detrusor muscle is present. The boxed area is shown at higher magnification in B. B: CIS of the urothelium, best maintained in a fold but also in adjacent flat urothelium. Accompanying mild chronic edematous cystitis in the adjacent stroma. Scale bars: $5 \mathrm{~mm}$ (A); $250 \mu \mathrm{m}$ (B).

\section{Fluorescence in Situ Hybridization}

To validate NGS-based detection of MDM2 gene amplification, fluorescence in situ hybridization was performed on corresponding formalin-fixed, paraffin-embedded tissue samples using the ZytoLight SPEC MDM2/CEN 12 Dual Color Probe (ZytoVision GmbH, Bremerhaven, Germany). The test is based on the use of two fluorescently labeled oligonucleotide probes: a $M D M 2$-specific probe (green fluorochrome $\mathrm{ZyGreen)}$ and a probe targeting the centromeric region of chromosome 12 (orange fluorochrome ZyOrange) on which the MDM2 locus is located. The test was performed according to the manufacturer's instructions. In brief, deparaffinized and rehydrated tissue sections were immersed in pretreatment buffer for 20 minutes at $98^{\circ} \mathrm{C}$, followed by enzymatic pepsin digestion for 10 minutes at $37^{\circ} \mathrm{C}$. Subsequently, the dual-color probe was applied to the tissue sections, followed by DNA denaturation at $75^{\circ} \mathrm{C}$ and a hybridization step at $37^{\circ} \mathrm{C}$ overnight. After stringent washing and DAPI counterstaining, hybridized probes were visualized by fluorescence microscopy (Axiovert S135 microscope; Zeiss). A minimum of 50 nuclei per case was analyzed, and the mean ratio of green (MDM2) over orange (CEN 12) hybridization signals was calculated. A case showing a ratio of $>2.0$ was considered $M D M 2$-amplified.

\section{Results}

The NGS tissue cohort comprised 25 fresh-frozen urothelial CIS samples from 25 cystectomy specimens of 5 female and 20 male patients with a mean age of 69 years (range, 43 to 82 years). For control purposes, five normal smooth muscle samples were also included in the cohort. Tumor multifocality was observed in $96 \%$ (24/25) of cystectomies, and $80 \%(20 / 25)$ of patients exhibited muscle-invasive disease. Of the patients, $80 \%(20 / 25)$ did not receive pretreatment before cystectomy (Table 1 and Supplemental Table S1).

Mutations and CNVs in 31 genes (Supplemental Table S2) were analyzed. In total, 108 GAs (mutations and CNVs), including multiple aberrations per gene, were identified in 25 LCM-isolated CIS samples, with an average of 4.3 alterations per sample (range, 0 to 13) (Supplemental Tables S3 and S4). Affected genes per CIS case are summarized in Figure 2. With $52 \%(13 / 25)$ of affected cases, TERT gene promoter mutations were the most frequent GAs detected (Figure 2). Of CIS specimens, $72 \%(18 / 25)$ harbored at least one GA in genes of the TP53/cell cycle pathway (TP53, MDM2, CCND1, $C D K N 1 A, C D K N 2 A, C C N E 1$, and $F B X W 7$ ). Genes encoding chromatin-modifying proteins (ARIDIA, KDM6A, CREBBP, and $E P 300$ ) were impacted with a similar frequency of $68 \%$ $(17 / 25)$ of cases. Moreover, DNA damage response genes (BRCA2, ATM, BRCA1, and ERCC2) exhibited variants in $60 \%(15 / 25)$ and phosphatidylinositol 3-kinase/mitogenactivated protein kinase pathway genes (ERBB2, FGFR1, $P I K 3 C A, E G F R, R A F 1$, and NF1) exhibited variants in $36 \%$ $(9 / 25)$ of CIS patients. The validity of the CNV data was approved in fluorescence in situ hybridization experiments exemplarily performed for $M D M 2$ (Supplemental Figure S1).

Of all GAs (mutations and CNVs), 86\% (93/108) were considered potentially actionable, including variants of yet unknown significance in genes with predictive potential (Supplemental Tables S3 and S4). On average, 3.7 potentially actionable GAs were detected per patient (range, 0 to 11 ); and $92 \%$ (23/25) of CIS cases harbored at least one GA in genes potentially impacting the selection of targeted therapies. Frequently altered genes found in CIS that were considered potentially actionable and potential related therapeutic options are summarized in Figure 3 and are listed in detail in Supplemental Table S5. ${ }^{23-66}$

\section{Discussion}

In contrast to MIBC, the molecular characterization of NMIBC lacks behind. ${ }^{21,67}$ Although the number of studies addressing this lack of knowledge is increasing, ${ }^{18,19,68-70}$ most work studying NMIBC by NGS spared aggressive CIS lesions, probably because of difficulties related to limited availability of tissue material. ${ }^{21,71}$ To the best of our knowledge, the present work studied the currently largest cohort of urothelial CIS samples of the urinary bladder using an NGS-based approach to identify GAs with the 

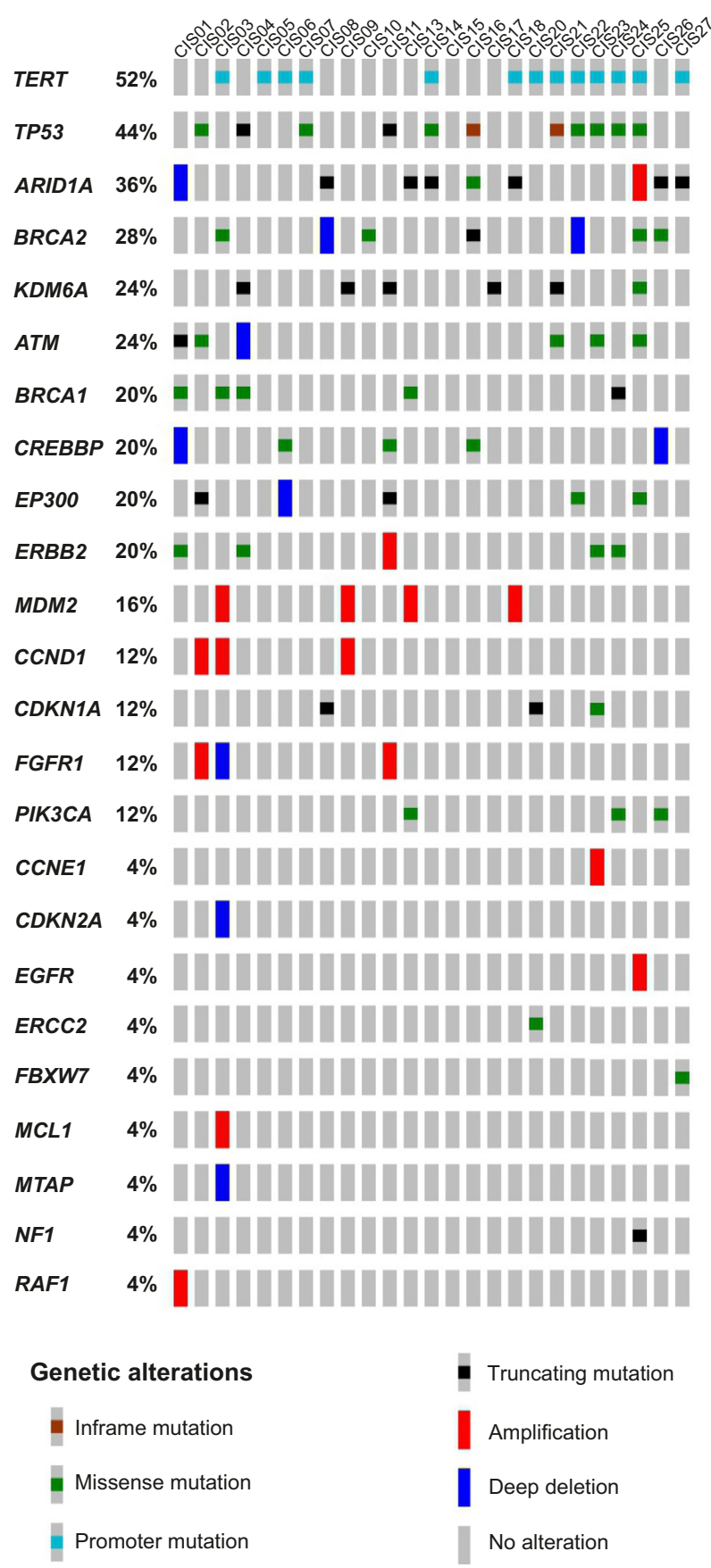

Figure 2 Mutations and copy number variations identified in a cohort of 25 laser-capture microdissected, fresh-frozen urothelial carcinoma in situ (CIS) samples. Analyzed genes without detected alterations are not shown.

potential to guide the investigation of targeted therapies in future clinical trials.

With a frequency of 52\%, TERT gene promoter mutations were the most common genetic alterations in our CIS cohort; that is comparable to mutational rates in CIS observed in earlier studies. ${ }^{19,72}$ TERT promoter mutations detected in the present study were confined to two hot spot positions recently described in bladder cancer ${ }^{73}$ (namely, to the positions -124 and -146 bp upstream of the ATG translation start codon in $77 \%$ and $23 \%$ of TERT-mutated cases, respectively).

In accordance with the proposed model of a distinct development of papillary and flat urothelial lesions, ${ }^{2}$ CIS cases in our study were characterized by frequent TP53 mutations (44\%), but complete absence of activating FGFR3 alterations. Deletions in the CDKN2A gene locus were detected at obviously lower frequency in our cohort (4\%) compared with MIBC cases of nonpapillary origin $(31 \%),{ }^{20}$ which is in accordance with observations made in two recent NMIBC studies. ${ }^{19,69}$ The observed discrepancy might be attributable to a lower sensitivity of our amplicon-based CNV detection method compared with the array-based technology applied in the MIBC The Cancer Genome Atlas study ${ }^{20}$ or might be related to CIS biology.

In addition to frequent aberrations in the TP53/cell cycle pathway (72\%), genes encoding chromatin-modifying proteins (ARIDIA, KDM6A, CREBBP, and EP300) were found to be altered at a similar rate (68\%), followed by aberrations in DNA damage repair-associated genes (BRCA2, ATM, $B R C A 1$, and $E R C C 2$ ) in $60 \%$ of the analyzed CIS samples. A high prevalence of alterations in chromatin-modifying and DNA damage pathway genes in high-grade NMIBC ${ }^{19}$ and $\mathrm{MIBC}^{20}$ has been noted before.

More important, $92 \%$ of CIS patients harbored at least one GA potentially predicting response to targeted therapy. Of these, TP53 was the most frequently mutated gene analyzed in this study. Although p53 itself is not a therapeutic target, recent data suggest that TP53-mutated cancer cells, showing a defective $G_{1}$ checkpoint, rely on an intact $\mathrm{G}_{2}-\mathrm{M}$ cell cycle checkpoint to ensure cell cycle arrest and repair in case of DNA damage. ${ }^{24}$ Inhibition of either of the two kinases WEE1 G2 checkpoint kinase (WEE1) or checkpoint kinase 1 (CHEK1), regulating $\mathrm{G}_{2}-\mathrm{M}$ checkpoint activation, resulted in synthetic lethality in TP53-mutant cells. More important, combination of a WEE1/CHEK1 inhibitor with a DNA-damaging drug enhanced cancer cell death. ${ }^{24}$ In bladder cancer, a similar reliance on an intact $\mathrm{G}_{2}-\mathrm{M}$ checkpoint was noted, especially in TP53/CDKN1A double-mutant cells. ${ }^{23}$ WEE1/CHEK1 inhibitors are currently investigated in clinical trials in solid tumors showing cell cycle/DNA repair defects (including TP53 mutations) as monotherapy or in combination with DNA-damage inducing drugs, such as US Food and Drug Administration-approved poly (ADP-ribose) polymerase (PARP) inhibitors (https://clinicaltrials.gov; NCT02797964 and NCT03330847).

Alterations in ARIDIA have been observed in $36 \%$ of CIS cases, comprising a high portion of samples harboring inactivating truncating mutations and gene deletions $(78 \%)$. AT-rich interaction domain 1A (ARID1A) is a component of switch/sucrose non-fermentable chromatin remodeling complexes, potential tumor suppressors that are mutated in approximately $20 \%$ across human cancers. ${ }^{74}$ Inactivation of switch/sucrose non-fermentable complexes, including 


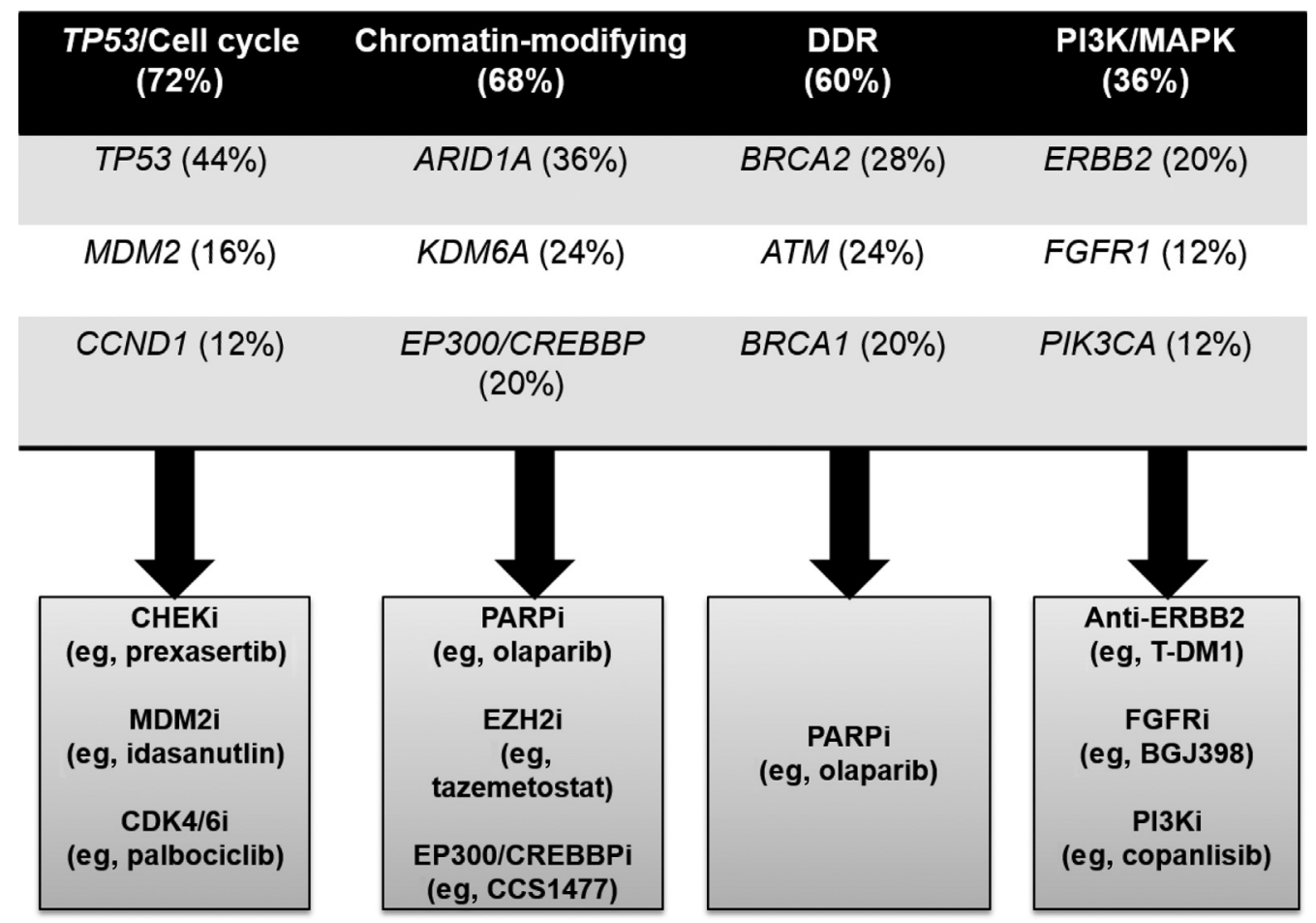

Figure 3 Potentially actionable genomic carcinoma in situ (CIS) alterations and suggested targeted drugs. Top: Impacted pathways and frequency of CIS cases harboring at least one potentially actionable genomic alteration in the respective pathway. The three most frequently affected genes of each pathway are depicted. Bottom: Potential targeted therapies. CDK4/6i, cyclin dependent kinase 4/6 inhibitor; CHEKi, checkpoint kinase inhibitor; CREBBPi, CREB binding protein inhibitor; DDR, DNA damage response; EP300, E1A binding protein p300; ERBB2, erb-b2 receptor tyrosine kinase 2; EZH2i, enhancer of zeste 2 polycomb repressive complex 2 subunit inhibitor; FGFRi, fibroblast growth factor receptor inhibitor; MAPK, mitogen-activated protein kinase; MDM2i, MDM2 proto-oncogene inhibitor; PARPi, poly (ADP-ribose) polymerase inhibitor; PI3K, phosphatidylinositol 3-kinase; PI3Ki, phosphatidylinositol 3-kinase inhibitor.

ARID1A deficiency, has been proposed to be a predictive biomarker for a plethora of targeted therapies in cancer. $^{25-27,29}$ For example, it has been observed that ARID1A loss of function disabled cell cycle checkpoint activation and thus proper DNA repair, sensitizing cells to PARP inhibitors. ${ }^{25}$ Other data suggested that ARID1A deficiency might impair DNA topoisomerase II alpha function, resulting in an accumulation of DNA lesions and thus enhanced reliance on ATR serine/threonine kinase activity for checkpoint activation and repair. ${ }^{26,75}$ The authors demonstrated that application of ATR serine/threonine kinase inhibitors, currently tested in clinical trials in advanced bladder cancer and other solid tumors (https://clinicaltrials. gov; NCT03682289 and NCT02567409), might be a rational therapy for ARID1A-deficient carcinomas. ${ }^{26}$

In addition to ARIDIA alterations potentially enhancing response to PARP inhibitors, $56 \%$ of CIS samples in this study exhibited at least one GA in the DNA damage repair genes $B R C A 1, B R C A 2$, and $A T M$, including pathogenic missense variants, gene deletions, and missense mutations of unknown significance. Inactivation of homologous recombination-associated genes is known to sensitize cancer cells to PARP inhibition. ${ }^{32}$ The potential benefit of PARP inhibitors is currently studied in patients with advanced bladder cancer (https://clinicaltrials.gov; NCT03375307 and
NCT03397394). Moreover, alterations in DNA damage response and repair-related genes, including BRCAl, $B R C A 2, A T M$, and ERCC2 (impacted in $60 \%$ of samples analyzed in this study), have been associated with improved response to platinum chemotherapy in advanced urothelial carcinoma. ${ }^{31}$ Cisplatin-based combination therapies, currently studied in high-risk NMIBC (https://clinicaltrials. gov; NCT02202772), might represent a bladder-preserving treatment option for a subgroup of CIS patients.

Other genes encoding chromatin-modifying proteins have been found to be frequently altered in our CIS cohort (namely, KDM6A in $24 \%$ of cases as well as CREBBP and EP300 in $20 \%$ of samples each). Concerning KDM6A, encoding a histone lysine demethylase,${ }^{76}$ most altered cases $(83 \%)$ harbored inactivating truncating mutations, as noted recently in NMIBC. ${ }^{19,68}$ More important, preclinical data showed that lysine demethylase 6A deficiency sensitized bladder cancer cells to inhibition of enhancer of zeste 2 polycomb repressive complex 2 subunit (EZH2), antagonizing lysine demethylase 6A activity ${ }^{34}$; and a scheduled clinical trial (https://clinicaltrials.gov; NCT03854474) in advanced bladder cancer now aims to study the potential benefit of combined pembrolizumab and tazemetostat (EZH2 inhibitor) therapy. Inactivating truncating mutations or gene deletions in either CREBBP or EP300, 
encoding two homologous histone acetyltransferases, ${ }^{77}$ were detected in $20 \%$ of CIS cases in this study. Although recent clinical data do not support the use of histone deacetylase inhibitors for treatment of CREBBP/EP300mutated bladder cancers, ${ }^{36}$ a synthetic lethal relationship between E1A binding protein p300 (EP300) and CREB binding protein (CREBBP) has been described in cancer cells $^{37}$ and might have potential for bladder cancer therapy as EP300/CREBBP bromodomain inhibitors have recently entered clinical trials (https://clinicaltrials.gov; NCT03568656).

Another important finding of this study is the presence of alterations in known therapeutic drug target genes of the phosphatidylinositol 3-kinase/mitogen-activated protein kinase pathway [namely, ERBB2 (20\%), FGFRI and PIK3CA (both 12\%), and EGFR and RAF1 (both 4\%)]. The ERBB2 locus was altered by amplification (4\%) and missense mutations in the extracellular domain (16\%), including the pathogenic activating S310F mutation ${ }^{78}$ and a variant of unknown significance in two cases each. ERBB2 amplification is a relatively rare event in CIS, ${ }^{38}$ and variants impacting amino acid position $\mathrm{S} 310(\mathrm{~S} 310 \mathrm{~F} / \mathrm{Y})$ are the most frequent missense mutations found in ERBB2 in bladder cancer. ${ }^{20}$ Although ERBB2-targeted therapies are US Food and Drug Administration-approved for ERBB2-positive breast and gastric cancer, ${ }^{79}$ results of previous clinical trials in advanced bladder, using drugs inhibiting ERBB2 signaling (trastuzumab and lapatinib), are inconsistent. ${ }^{80-82}$ More important, we have recently demonstrated moderate to strong positivity for ERBB2 in 65\% of CIS samples and only weak expression in adjacent normal urothelium. ${ }^{38}$ Thus, as the driver status of ERBB2 in bladder cancer is unclear, ${ }^{83}$ antibody-drug conjugates, such as trastuzumab emtansine (T-DM1), are suggested as a rational therapy for urothelial CIS, supported by preclinical data in bladder cancer. ${ }^{39}$ Clinical trials in late-stage bladder cancer investigating T-DM1 are underway, but results are not available yet (https://clinicaltrials.gov; eg, NCT02999672).

Although this work comprises the currently largest cohort of urothelial CIS samples analyzed by an NGS-based approach, it is limited to carefully mapped frozen cystectomy samples to find unequivocal and sufficient material for analysis. Larger-scale studies are needed to validate these findings and may partially be possible by targeted analysis of formalin-fixed transurethral resection samples, for which we have an extended data base. ${ }^{38}$ Also, this sequencing study was focused on a specific gene set; and it is meaningful to perform more comprehensive analyses of this entity in upcoming studies. More important, because of our primary motive of finding therapy targets, matched control samples were not analyzed for each CIS case and a certain discrimination of germline and somatic variants was thus not possible.

In summary, targeted NGS of fresh-frozen urothelial CIS samples identified at least one potentially actionable alteration in most CIS cases. These data should help in guiding the selection of targeted intravesical/systemic therapies that should be investigated in future clinical trials.

\section{Acknowledgments}

We thank Angela Maurer (University Hospital RheinischWestfälische Technische Hochschule Aachen) for supporting the assessment of the next-generation sequencing data.

\section{Author Contributions}

S.G. and R.K. conceptualized the study; S.G., N.O.-B., U.S., and K.G. designed the methods; S.G., U.S., and I.L. performed the experiments; N.O.-B., K.G., and S.G. analyzed the results; K.G. and N.O.-B. developed the inhouse software for CNV analysis; S.G. wrote the manuscript; and E.L., N.O.-B., R.K., N.T.G., I.L., A.H., K.G., U.S., and K.L.-D. edited the manuscript; N.T.G., K.L.-D., and A.H. provided resources; S.G. and R.K. supervised the study; S.G. acquired funding.

\section{Supplemental Data}

Supplemental material for this article can be found at https://doi.org/10.1016/j.ajpath.2019.10.004.

\section{References}

1. Ferlay J, Shin H-R, Bray F, Forman D, Mathers C, Parkin DM: Estimates of worldwide burden of cancer in 2008: GLOBOCAN 2008. Int J Cancer 2010, 127:2893-2917

2. Knowles MA, Hurst CD: Molecular biology of bladder cancer: new insights into pathogenesis and clinical diversity. Nat Rev Cancer 2015, 15:25-41

3. Kirkali Z, Chan T, Manoharan M, Algaba F, Busch C, Cheng L, Kiemeney L, Kriegmair M, Montironi R, Murphy WM Sesterhenn IA, Tachibana M, Weider J: Bladder cancer: epidemiology, staging and grading, and diagnosis. Urology 2005, 66:4-34

4. Casey RG, Catto JWF, Cheng L, Cookson MS, Herr H, Shariat S, Witjes JA, Black PC: Diagnosis and management of urothelial carcinoma in situ of the lower urinary tract: a systematic review. Eur Urol 2015, 67:876-888

5. Sylvester RJ, van der Meijden A, Witjes JA, Jakse G, Nonomura N, Cheng C, Torres A, Watson R, Kurth KH: High-grade Ta urothelial carcinoma and carcinoma in situ of the bladder. Urology 2005, 66: 90-107

6. Babjuk M, Burger M, Zigeuner R, Shariat SF, van Rhijn BWG, Compérat E, Sylvester RJ, Kaasinen E, Böhle A, Palou Redorta J, Rouprêt M: EAU guidelines on non-muscle-invasive urothelial carcinoma of the bladder: update 2013. Eur Urol 2013, 64: 639-653

7. Alfred Witjes J, Lebret T, Compérat EM, Cowan NC, De Santis M, Bruins HM, Hernández V, Espinós EL, Dunn J, Rouanne M, Neuzillet Y, Veskimäe E, van der Heijden AG, Gakis G, Ribal MJ: Updated 2016 EAU guidelines on muscle-invasive and metastatic bladder cancer. Eur Urol 2017, 71:462-475

8. Bellmunt J, Powles T, Vogelzang NJ: A review on the evolution of PD-1/PD-L1 immunotherapy for bladder cancer: the future is now. Cancer Treat Rev 2017, 54:58-67 
9. Tripathi A, Plimack ER: Immunotherapy for urothelial carcinoma: current evidence and future directions. Curr Urol Rep 2018, 19:109

10. Sharma P, Hu-Lieskovan S, Wargo JA, Ribas A: Primary, adaptive, and acquired resistance to cancer immunotherapy. Cell 2017, 168: 707-723

11. Hall MC, Chang SS, Dalbagni G, Pruthi RS, Seigne JD, Skinner EC, Wolf JS, Schellhammer PF: Guideline for the management of nonmuscle invasive bladder cancer (stages Ta, T1, and Tis): 2007 update. J Urol 2007, 178:2314-2330

12. Tang DH, Chang SS: Management of carcinoma in situ of the bladder: best practice and recent developments. Ther Adv Urol 2015, 7:351-364

13. Herr HW, Sogani PC: Does early cystectomy improve the survival of patients with high risk superficial bladder tumors? J Urol 2001, 166: 1296-1299

14. Nykopp TK, Batista da Costa J, Mannas M: Black PC: Current clinical trials in non-muscle invasive bladder cancer. Curr Urol Rep 2018, 19:101

15. TCGA Research Network: Comprehensive molecular characterization of urothelial bladder carcinoma. Nature 2014, 507:315-322

16. Ross JS, Wang K, Al-Rohil RN, Nazeer T, Sheehan CE, Otto GA, He J, Palmer G, Yelensky R, Lipson D, Ali S, Balasubramanian S, Curran JA, Garcia L, Mahoney K, Downing SR, Hawryluk M, Miller VA, Stephens PJ: Advanced urothelial carcinoma: nextgeneration sequencing reveals diverse genomic alterations and targets of therapy. Mod Pathol 2014, 27:271-280

17. Kim PH, Cha EK, Sfakianos JP, Iyer G, Zabor EC, Scott SN, Ostrovnaya I, Ramirez R, Sun A, Shah R, Yee AM, Reuter VE, Bajorin DF, Rosenberg JE, Schultz N, Berger MF, Al-Ahmadie HA, Solit DB, Bochner BH: Genomic predictors of survival in patients with high-grade urothelial carcinoma of the bladder. Eur Urol 2015, 67:198-201

18. Hedegaard J, Lamy P, Nordentoft I, Algaba F, Høyer S, Ulhøi BP, et al: Comprehensive transcriptional analysis of early-stage urothelial carcinoma. Cancer Cell 2016, 30:27-42

19. Pietzak EJ, Bagrodia A, Cha EK, Drill EN, Iyer G, Isharwal S, Ostrovnaya I, Baez P, Li Q, Berger MF, Zehir A, Schultz N, Rosenberg JE, Bajorin DF, Dalbagni G, Al-Ahmadie H, Solit DB, Bochner BH: Next-generation sequencing of nonmuscle invasive bladder cancer reveals potential biomarkers and rational therapeutic targets. Eur Urol 2017, 72:952-959

20. Robertson AG, Kim J, Al-Ahmadie H, Bellmunt J, Guo G, Cherniack $\mathrm{AD}$, et al: Comprehensive molecular characterization of muscle-invasive bladder cancer. Cell 2017, 171:540-556.e25

21. Rentsch CA, Müller DC, Ruiz C, Bubendorf L: Comprehensive molecular characterization of urothelial bladder carcinoma: a step closer to clinical translation? Eur Urol 2017, 72:960-961

22. Cerami E, Gao J, Dogrusoz U, Gross BE, Sumer SO, Aksoy BA, Jacobsen A, Byrne CJ, Heuer ML, Larsson E, Antipin Y, Reva B, Goldberg AP, Sander C, Schultz N: The cBio cancer genomics portal: an open platform for exploring multidimensional cancer genomics data. Cancer Discov 2012, 2:401-404

23. Liu Y, Kwiatkowski DJ: Combined CDKN1A/TP53 mutation in bladder cancer is a therapeutic target. Mol Cancer Ther 2015, 14: $174-182$

24. Moser R, Xu C, Kao M, Annis J, Lerma LA, Schaupp CM, Gurley KE, Jang IS, Biktasova A, Yarbrough WG, Margolin AA, Grandori C, Kemp CJ, Méndez E: Functional kinomics identifies candidate therapeutic targets in head and neck cancer. Clin Cancer Res 2014, 20:4274-4288

25. Shen J, Peng Y, Wei L, Zhang W, Yang L, Lan L, Kapoor P, Ju Z, Mo Q, Shih I-M, Uray IP, Wu X, Brown PH, Shen X, Mills GB, Peng G: ARID1A deficiency impairs the DNA damage checkpoint and sensitizes cells to PARP inhibitors. Cancer Discov 2015, 5:752-767

26. Williamson CT, Miller R, Pemberton HN, Jones SE, Campbell J, Konde A, Badham N, Rafiq R, Brough R, Gulati A, Ryan CJ, Francis J, Vermulen PB, Reynolds AR, Reaper PM, Pollard JR,
Ashworth A, Lord CJ: ATR inhibitors as a synthetic lethal therapy for tumours deficient in ARID1A. Nat Commun 2016, 7:13837

27. Samartzis EP, Gutsche K, Dedes KJ, Fink D, Stucki M, Imesch P: Loss of ARID1A expression sensitizes cancer cells to PI3K- and AKT-inhibition. Oncotarget 2014, 5:5295-5303

28. Shen J, Ju Z, Zhao W, Wang L, Peng Y, Ge Z, Nagel ZD, Zou J, Wang C, Kapoor P, Ma X, Ma D, Liang J, Song S, Liu J, Samson LD, Ajani JA, Li G-M, Liang H, Shen X, Mills GB, Peng G: ARID1A deficiency promotes mutability and potentiates therapeutic antitumor immunity unleashed by immune checkpoint blockade. Nat Med 2018, 24:556-562

29. Bitler BG, Aird KM, Garipov A, Li H, Amatangelo M, Kossenkov AV, Schultz DC, Liu Q, Shih I-M, Conejo-Garcia JR, Speicher DW, Zhang R: Synthetic lethality by targeting EZH2 methyltransferase activity in ARID1A-mutated cancers. Nat Med 2015, 21:231-238

30. Farmer H, McCabe N, Lord CJ, Tutt ANJ, Johnson DA, Richardson TB, Santarosa M, Dillon KJ, Hickson I, Knights C, Martin NMB, Jackson SP, Smith GCM, Ashworth A: Targeting the DNA repair defect in BRCA mutant cells as a therapeutic strategy. Nature 2005, 434:917-921

31. Teo MY, Bambury RM, Zabor EC, Jordan E, Al-Ahmadie H, Boyd ME, Bouvier N, Mullane SA, Cha EK, Roper N, Ostrovnaya I, Hyman DM, Bochner BH, Arcila ME, Solit DB, Berger MF, Bajorin DF, Bellmunt J, Iyer G, Rosenberg JE: DNA damage response and repair gene alterations are associated with improved survival in patients with platinum-treated advanced urothelial carcinoma. Clin Cancer Res 2017, 23:3610-3618

32. McCabe N, Turner NC, Lord CJ, Kluzek K, Bialkowska A, Swift S, Giavara S, O’Connor MJ, Tutt AN, Zdzienicka MZ, Smith GCM, Ashworth A: Deficiency in the repair of DNA damage by homologous recombination and sensitivity to poly(ADP-ribose) polymerase inhibition. Cancer Res 2006, 66:8109-8115

33. Liu Q, Gheorghiu L, Drumm M, Clayman R, Eidelman A, Wszolek MF, Olumi A, Feldman A, Wang M, Marcar L, Citrin DE, Wu C-L, Benes CH, Efstathiou JA, Willers H: PARP-1 inhibition with or without ionizing radiation confers reactive oxygen speciesmediated cytotoxicity preferentially to cancer cells with mutant TP53. Oncogene 2018, 37:2793-2805

34. Ler LD, Ghosh S, Chai X, Thike AA, Heng HL, Siew EY, Dey S, Koh LK, Lim JQ, Lim WK, Myint SS, Loh JL, Ong P, Sam XX, Huang D, Lim T, Tan PH, Nagarajan S, Cheng CWS, Ho H, Ng LG, Yuen J, Lin P-H, Chuang C-K, Chang Y-H, Weng W-H, Rozen SG, Tan P, Creasy CL, Pang S-T, McCabe MT, Poon SL, Teh BT: Loss of tumor suppressor KDM6A amplifies PRC2-regulated transcriptional repression in bladder cancer and can be targeted through inhibition of EZH2. Sci Trans1 Med 2017, 9:eaai8312

35. Andersen C, Asmar F, Klausen T, Hasselbalch H, Gronbaek K: Somatic mutations of the CREBBP and EP300 genes affect response to histone deacetylase inhibition in malignant DLBCL clones. Leuk Res Rep 2012, 8:1-3

36. Grivas P, Mortazavi A, Picus J, Hahn NM, Milowsky MI, Hart LL, Alva A, Bellmunt J, Pal SK, Bambury RM, O’Donnell PH, Gupta S, Guancial EA, Sonpavde GP, Faltaos D, Potvin D, Christensen JG, Chao RC, Rosenberg JE: Mocetinostat for patients with previously treated, locally advanced/metastatic urothelial carcinoma and inactivating alterations of acetyltransferase genes. Cancer 2019, 125: $533-540$

37. Ogiwara H, Sasaki M, Mitachi T, Oike T, Higuchi S, Tominaga Y, Kohno T: Targeting p300 addiction in CBP-deficient cancers causes synthetic lethality via apoptotic cell death due to abrogation of MYC expression. Cancer Discov 2015, 6:430-445

38. Barth I, Schneider U, Grimm T, Karl A, Horst D, Gaisa NT, Knüchel R, Garczyk S: Progression of urothelial carcinoma in situ of the urinary bladder: a switch from luminal to basal phenotype and related therapeutic implications. Virchows Arch 2018, 472:749-758

39. Hayashi T, Seiler R, Oo HZ, Jäger W, Moskalev I, Awrey S, Dejima T, Todenhöfer T, Li N, Fazli L, Matsubara A, Black PC: 
Targeting HER2 with T-DM1, an antibody cytotoxic drug conjugate, is effective in HER2 over expressing bladder cancer. J Urol 2015, 194:1120-1131

40. Her N-G, Oh J-W, Oh YJ, Han S, Cho HJ, Lee Y, Ryu GH, Nam D-H: Potent effect of the MDM2 inhibitor AMG232 on suppression of glioblastoma stem cells. Cell Death Dis 2018, 9:792

41. Chen L, Pastorino F, Berry P, Bonner J, Kirk C, Wood KM, Thomas HD, Zhao Y, Daga A, Veal GJ, Lunec J, Newell DR, Ponzoni M, Tweddle DA: Preclinical evaluation of the first intravenous small molecule MDM2 antagonist alone and in combination with temozolomide in neuroblastoma. Int J Cancer 2019, 144:3146-3159

42. Canon J, Osgood T, Olson SH, Saiki AY, Robertson R, Yu D, Eksterowicz J, Ye Q, Jin L, Chen A, Zhou J, Cordover D, Kaufman S, Kendall R, Oliner JD, Coxon A, Radinsky R: The MDM2 inhibitor AMG 232 demonstrates robust antitumor efficacy and potentiates the activity of p53-inducing cytotoxic agents. Mol Cancer Ther 2015, 14: 649-658

43. Gong X, Litchfield LM, Webster Y, Chio L-C, Wong SS, Stewart TR, Dowless M, Dempsey J, Zeng Y, Torres R, Boehnke K, Mur C, Marugán C, Baquero C, Yu C, Bray SM, Wulur IH, Bi C, Chu S, Qian H-R, Iversen PW, Merzoug FF, Ye XS, Reinhard C, De Dios A, Du J, Caldwell CW, Lallena MJ, Beckmann RP, Buchanan SG: Genomic aberrations that activate D-type cyclins are associated with enhanced sensitivity to the CDK4 and CDK6 inhibitor abemaciclib. Cancer Cell 2017, 32:761-776.e6

44. Pan Q, Sathe A, Black PC, Goebell PJ, Kamat AM, Schmitz-Draeger B, Nawroth R: CDK4/6 inhibitors in cancer therapy: a novel treatement strategy for bladder cancer. Bladder Cancer 2017, 3:79-88

45. Rubio C, Martínez-Fernández M, Segovia C, Lodewijk I, SuarezCabrera C, Segrelles C, López-Calderón F, Munera-Maravilla E, Santos M, Bernardini A, García-Escudero R, Lorz C, GómezRodriguez MJ, de Velasco G, Otero I, Villacampa F, GuerreroRamos F, Ruiz S, de la Rosa F, Domínguez-Rodríguez S, Real FX, Malats N, Castellano D, Dueñas M, Paramio JM: CDK4/6 inhibitor as a novel therapeutic approach for advanced bladder cancer independently of RB1 status. Clin Cancer Res 2019, 25:390-402

46. Zeng S-X, Zhu Y, Ma A-H, Yu W, Zhang H, Lin T-Y, Shi W, Tepper CG, Henderson PT, Airhart S, Guo J-M, Xu C-L, deVere White RW, Pan C-X: The phosphatidylinositol 3-kinase pathway as a potential therapeutic target in bladder cancer. Clin Cancer Res 2017, 23:6580-6591

47. Ross RL, McPherson HR, Kettlewell L, Shnyder SD, Hurst CD, Alder O, Knowles MA: PIK3CA dependence and sensitivity to therapeutic targeting in urothelial carcinoma. BMC Cancer 2016, $16: 553$

48. Tadesse S, Caldon EC, Tilley W, Wang S: Cyclin-dependent kinase 2 inhibitors in cancer therapy: an update. J Med Chem 2019, 62: 4233-4251

49. Karkera JD, Cardona GM, Bell K, Gaffney D, Portale JC, SantiagoWalker A, Moy CH, King P, Sharp M, Bahleda R, Luo FR, Alvarez JD, Lorenzi MV, Platero SJ: Oncogenic characterization and pharmacologic sensitivity of activating fibroblast growth factor receptor (FGFR) genetic alterations to the selective FGFR inhibitor erdafitinib. Mol Cancer Ther 2017, 16:1717-1726

50. Grünewald S, Politz O, Bender S, Héroult M, Lustig K, Thuss U, Kneip C, Kopitz C, Zopf D, Collin MP, Boemer U, Ince S, Ellinghaus P, Mumberg D, Hess-Stumpp H, Ziegelbauer K: Rogaratinib: a potent and selective pan-FGFR inhibitor with broad antitumor activity in FGFR-overexpressing preclinical cancer models. Int J Cancer 2019, 145:1346-1357

51. Nogova L, Sequist LV, Perez Garcia JM, Andre F, Delord J-P, Hidalgo M, Schellens JHM, Cassier PA, Camidge DR, Schuler M, Vaishampayan U, Burris H, Tian GG, Campone M, Wainberg ZA, Lim W-T, LoRusso P, Shapiro GI, Parker K, Chen X, Choudhury S, Ringeisen F, Graus-Porta D, Porter D, Isaacs R, Buettner R, Wolf J: Evaluation of BGJ398, a fibroblast growth factor receptor 1-3 kinase inhibitor, in patients with advanced solid tumors harboring genetic alterations in fibroblast growth factor receptors: results of a global phase I, dose-escalation and dose-expansion study. J Clin Oncol 2017, 35:157-165

52. Cocco E, Lopez S, Black J, Bellone S, Bonazzoli E, Predolini F, Ferrari F, Schwab CL, Menderes G, Zammataro L, Buza N, Hui P, Wong S, Zhao S, Bai Y, Rimm DL, Ratner E, Litkouhi B, Silasi D-A, Azodi M, Schwartz PE, Santin AD: Dual CCNE1/PIK3CA targeting is synergistic in CCNE1-amplified/PIK3CA-mutated uterine serous carcinomas in vitro and in vivo. Br J Cancer 2016, 115:303-311

53. Konecny GE, Winterhoff B, Kolarova T, Qi J, Manivong K, Dering J, Yang G, Chalukya M, Wang H-J, Anderson L, Kalli KR, Finn RS, Ginther C, Jones S, Velculescu VE, Riehle D, Cliby WA, Randolph S, Koehler M, Hartmann LC, Slamon DJ: Expression of p16 and retinoblastoma determines response to CDK4/6 inhibition in ovarian cancer. Clin Cancer Res 2011, 17:1591-1602

54. Sathe A, Koshy N, Schmid SC, Thalgott M, Schwarzenböck SM, Krause BJ, Holm PS, Gschwend JE, Retz M, Nawroth R: CDK4/6 inhibition controls proliferation of bladder cancer and transcription of RB1. J Urol 2016, 195:771-779

55. Rose TL, Chism DD, Alva AS, Deal AM, Maygarden SJ, Whang YE, Kardos J, Drier A, Basch E, Godley PA, Dunn MW, Kim WY, Milowsky MI: Phase II trial of palbociclib in patients with metastatic urothelial cancer after failure of first-line chemotherapy. Br J Cancer 2018, 119:801-807

56. Rebouissou S, Bernard-Pierrot I, de Reyniès A, Lepage M-L, Krucker C, Chapeaublanc E, Hérault A, Kamoun A, Caillault A, Letouzé E, Elarouci N, Neuzillet Y, Denoux Y, Molinié V, Vordos D, Laplanche A, Maillé P, Soyeux P, Ofualuka K, Reyal F, Biton A, Sibony M, Paoletti X, Southgate J, Benhamou S, Lebret T, Allory Y, Radvanyi F: EGFR as a potential therapeutic target for a subset of muscle-invasive bladder cancers presenting a basal-like phenotype. Sci Transl Med 2014, 6:244ra91

57. Siddiqui MR, Railkar R, Sanford T, Crooks DR, Eckhaus MA, Haines D, Choyke PL, Kobayashi H, Agarwal PK: Targeting epidermal growth factor receptor (EGFR) and human epidermal growth factor receptor 2 (HER2) expressing bladder cancer using combination photoimmunotherapy (PIT). Sci Rep 2019, 9:2084

58. Powles T, Huddart RA, Elliott T, Sarker S-J, Ackerman C, Jones R, Hussain S, Crabb S, Jagdev S, Chester J, Hilman S, Beresford M, Macdonald G, Santhanam S, Frew JA, Stockdale A, Hughes S, Berney D, Chowdhury S: Phase III, double-blind, randomized trial that compared maintenance lapatinib versus placebo after first-line chemotherapy in patients with human epidermal growth factor receptor $1 / 2$ - positive metastatic bladder cancer. J Clin Oncol 2017, 35:48-55

59. Autenrieth ME, Seidl C, Bruchertseifer F, Horn T, Kurtz F, Feuerecker B, D’Alessandria C, Pfob C, Nekolla S, Apostolidis C, Mirzadeh S, Gschwend JE, Schwaiger M, Scheidhauer K, Morgenstern A: Treatment of carcinoma in situ of the urinary bladder with an alpha-emitter immunoconjugate targeting the epidermal growth factor receptor: a pilot study. Eur J Nucl Med Mol Imaging 2018, 45:1364-1371

60. Mao J-H, Kim I-J, Wu D, Climent J, Kang HC, DelRosario R, Balmain A: FBXW7 targets mTOR for degradation and cooperates with PTEN in tumor suppression. Science 2008, 321:1499-1502

61. Caenepeel S, Brown SP, Belmontes B, Moody G, Keegan KS, Chui D, et al: AMG 176, a selective MCL1 inhibitor, is effective in hematologic cancer models alone and in combination with established therapies. Cancer Discov 2018, 8:1582-1597

62. Kotschy A, Szlavik Z, Murray J, Davidson J, Maragno AL, Le Toumelin-Braizat G, et al: The MCL1 inhibitor S63845 is tolerable and effective in diverse cancer models. Nature 2016, 538:477-482

63. Knievel J, Schulz W, Greife A, Hader C, Lübke T, Schmitz I, Albers P, Niegisch G: Multiple mechanisms mediate resistance to sorafenib in urothelial cancer. Int J Mol Sci 2014, 15:20500-20517

64. Necchi A, Lo Vullo S, Raggi D, Perrone F, Giannatempo P, Calareso G, Togliardi E, Nicolai N, Piva L, Biasoni D, Catanzaro M, Torelli T, Stagni S, Colecchia M, Busico A, Pennati M, Zaffaroni N, 
Mariani L, Salvioni R: Neoadjuvant sorafenib, gemcitabine, and cisplatin administration preceding cystectomy in patients with muscle-invasive urothelial bladder carcinoma: an open-label, singlearm, single-center, phase 2 study. Urol Oncol 2018, 36:8.e1-8.e8

65. Johannessen CM, Reczek EE, James MF, Brems H, Legius E, Cichowski K: The NF1 tumor suppressor critically regulates TSC2 and mTOR. Proc Natl Acad Sci U S A 2005, 102:8573-8578

66. Marjon K, Cameron MJ, Quang P, Clasquin MF, Mandley E, Kunii K, McVay M, Choe S, Kernytsky A, Gross S, Konteatis Z, Murtie J, Blake ML, Travins J, Dorsch M, Biller SA, Marks KM: MTAP deletions in cancer create vulnerability to targeting of the MAT2A/PRMT5/RIOK1 axis. Cell Rep 2016, 15:574-587

67. Sjödahl G, Jackson CL, Bartlett JMS, Siemens DR, Berman DM: Molecular profiling in muscle-invasive bladder cancer: more than the sum of its parts. J Pathol 2019, 247:563-573

68. Hurst CD, Alder O, Platt FM, Droop A, Stead LF, Burns JE, Burghel GJ, Jain S, Klimczak LJ, Lindsay H, Roulson J-A, Taylor CF, Thygesen H, Cameron AJ, Ridley AJ, Mott HR, Gordenin DA, Knowles MA: Genomic subtypes of non-invasive bladder cancer with distinct metabolic profile and female gender bias in KDM6A mutation frequency. Cancer Cell 2017, 32:701-715.e7

69. Scott SN, Ostrovnaya I, Lin CM, Bouvier N, Bochner BH, Iyer G, Solit D, Berger MF, Lin O: Next-generation sequencing of urine specimens: a novel platform for genomic analysis in patients with non-muscle-invasive urothelial carcinoma treated with bacille Calmette-Guérin. Cancer Cytopathol 2017, 125:416-426

70. Nassar AH, Umeton R, Kim J, Lundgren K, Harshman L, Van Allen EM, Preston M, Dong F, Bellmunt J, Mouw KW, Choueiri TK, Sonpavde G, Kwiatkowski DJ: Mutational analysis of 472 urothelial carcinoma across grades and anatomic sites. Clin Cancer Res 2019, $25: 2458-2470$

71. Hurst CD, Knowles MA: Mutational landscape of non-muscleinvasive bladder cancer. Urol Oncol 2018, [Epub ahead of print] doi:10.1016/j.urolonc.2018.10.015

72. Kinde I, Munari E, Faraj SF, Hruban RH, Schoenberg M, Bivalacqua T, Allaf M, Springer S, Wang Y, Diaz LA, Kinzler KW, Vogelstein B, Papadopoulos N, Netto GJ: TERT promoter mutations occur early in urothelial neoplasia and are biomarkers of early disease and disease recurrence in urine. Cancer Res 2013, 73:7162-7167

73. Hurst CD, Platt FM, Knowles MA: Comprehensive mutation analysis of the TERT promoter in bladder cancer and detection of mutations in voided urine. Eur Urol 2014, 65:367-369

74. Kadoch C, Hargreaves DC, Hodges C, Elias L, Ho L, Ranish J, Crabtree GR: Proteomic and bioinformatic analysis of mammalian SWI/SNF complexes identifies extensive roles in human malignancy. Nat Genet 2013, 45:592-601
75. Dykhuizen EC, Hargreaves DC, Miller EL, Cui K, Korshunov A, Kool M, Pfister S, Cho Y-J, Zhao K, Crabtree GR: BAF complexes facilitate decatenation of DNA by topoisomerase II $\alpha$. Nature 2013, 497:624-627

76. Schulz WA, Lang A, Koch J, Greife A: The histone demethylase UTX/KDM6A in cancer: progress and puzzles. Int J Cancer 2019, $145: 614-620$

77. Attar N, Kurdistani SK: Exploitation of EP300 and CREBBP lysine acetyltransferases by cancer. Cold Spring Harb Perspect Med 2017, 7: a026534

78. Greulich H, Kaplan B, Mertins P, Chen T-H, Tanaka KE, Yun C-H, Zhang X, Lee S-H, Cho J, Ambrogio L, Liao R, Imielinski M, Banerji S, Berger AH, Lawrence MS, Zhang J, Pho NH, Walker SR, Winckler W, Getz G, Frank D, Hahn WC, Eck MJ, Mani DR, Jaffe JD, Carr SA, Wong K-K, Meyerson M: Functional analysis of receptor tyrosine kinase mutations in lung cancer identifies oncogenic extracellular domain mutations of ERBB2. Proc Natl Acad Sci U S A 2012, 109:14476-14481

79. Meric-Bernstam F, Johnson AM, Dumbrava EEI, Raghav K, Balaji K, Bhatt M, Murthy RK, Rodon J, Piha-Paul SA: Advances in HER2-targeted therapy: novel agents and opportunities beyond breast and gastric cancer. Clin Cancer Res 2019, 25:2033-2041

80. Oudard S, Culine S, Vano Y, Goldwasser F, Théodore C, Nguyen T, Voog E, Banu E, Vieillefond A, Priou F, Deplanque G, Gravis G, Ravaud A, Vannetzel JM, Machiels J-P, Muracciole X, Pichon M-F, Bay J-O, Elaidi R, Teghom C, Radvanyi F, Beuzeboc P: Multicentre randomised phase II trial of gemcitabine+platinum, with or without trastuzumab, in advanced or metastatic urothelial carcinoma overexpressing Her2. Eur J Cancer 2015, 51:45-54

81. Wülfing C, Machiels J-PH, Richel DJ, Grimm M-O, Treiber U, De Groot MR, Beuzeboc P, Parikh R, Pétavy F, El-Hariry IA: A single-arm, multicenter, open-label phase 2 study of lapatinib as the second-line treatment of patients with locally advanced or metastatic transitional cell carcinoma. Cancer 2009, 115:2881-2890

82. Hainsworth JD, Meric-Bernstam F, Swanton C, Hurwitz H, Spigel DR, Sweeney C, Burris HA, Bose R, Yoo B, Stein A, Beattie M, Kurzrock R: Targeted therapy for advanced solid tumors on the basis of molecular profiles: results from MyPathway, an openlabel, phase IIa multiple basket study. J Clin Oncol 2018, 36: $536-542$

83. Kiss B, Wyatt AW, Douglas J, Skuginna V, Mo F, Anderson S, Rotzer D, Fleischmann A, Genitsch V, Hayashi T, Neuenschwander M, Buerki C, Davicioni E, Collins C, Thalmann GN, Black PC, Seiler R: Her2 alterations in muscleinvasive bladder cancer: patient selection beyond protein expression for targeted therapy. Sci Rep 2017, 7:42713 